\title{
СОВРЕМЕННАЯ КРИМИНОЛОГИЧЕСКАЯ ХАРАКТЕРИСТИКА ПРЕСТУПНОСТИ НЕСОВЕРШЕННОЛЕТНИХ КАК ОДНОГО ИЗ ВИДОВ ПРЕСТУПНОСТИ
}

\begin{abstract}
Аннотация: В настоящей статье рассматривается преступность несовершеннолетних в общей системе преступности. Отмечено, что преступность несовершеннолетних имеет ряд отличительных особенностей, которые проявляются в первую очередь в причинном комплексе и мотивации формирования преступного поведения и, как следствие, в ее уровне и тенденциях развития. Автор предлагает собственное определение преступности несовершеннолетних.Также статье отмечается, что в условиях нестабильной социально-экономической и политической ситуации самыми беззащитными оказались дети. Дети как никакая другая социальная группа самым непосредственным образом почувствовали на себе издержки демократических и экономических преобразований. Названные и ряд других проблем коснулись практически все семьи, в которых имел место весьма скромный заработок родителей, а также семьи, где в качестве родителя выступает один человек. Массовая алкоголизации, проблема наркомании взрослого населения, системная безработица лишила детей нормальных и ответственных родителей, а также заботливой семьи. Методологическую основу статьи составили современные достижения теории познания. В процессе исследования применялись общефилософский, теоретический, эмпирический методы (диалектика, системный метод, анализ, синтез, аналогия, дедукция, наблюдение, моделирование), традиционно-правовые методы (формально-логический), методы, используемые в конкретно-сочиологических исследованиях (статистические, экспертные оценки и др.). Несовершеннолетние в силу специфики их несформировавшейся психики, возрастных особенностей, а также социальной бессознательности очень быстро воспринимают все негативное, что происходит вокруг них, в этой связи данная категория населения оказалась весьма криминальной. В настоящее время практически каждое третье преступление против собственности совершенное на улице или ином общественном месте происходит с участием несовершеннолетнего. На сегодня уже можно говорить об организованной преступности несовершеннолетних, устойчивых экстремистских группах несовершеннолетних. Также приходиться признать, что ежегодно в нашей стране увеличивается количество детей начинающих употреблять алкоголь чуть ли не с шести-семи лет, растет детская наркомания, токсикомания, проституция, а количество административных правонарушений совершаемых несовершеннолетними уже давно исчисляется сотнями тысяч.
\end{abstract}

Ключевые слова: несовершеннолетние, деликтность, преступность, профилактика, полиция, детерминанты, возможность, форма, метод, дети.

$\Pi$ реступность является весьма сложным социально-правовым явлением. В научной литературе существуют десятки ее определений. По поводу возникновения преступности в том виде, в каком мы ее понимаем в настоящее время, высказаны различные мнения. С. В. Бородин, например, полагал, что процесс выделения преступности как самостоятельного правового и социального явления из более широкого круга нарушений норм права и морали происходил в течение длительного времени и закончился в позднем средневековье. В России этой исторической вехой можно считать, по-видимому, издание Соборного уложения (1649 г.), в котором уголовно-правовые нормы впервые были объединены в отдельные главы (хотя термин «преступление» еще не упоминался) ${ }^{1}$. Принятие Соборного уложения 1649 года (XVII век), по мнению С. Г. Олькова, - одна из наиболее ярких вех российского нормотворчества. Недаром историки называют его первым в нашей стране систематизированным законом ${ }^{2}$. Тем не менее, в России были еще Судебники 1497, 1550 годов, Новгородская судная грамота (X-XV вв.) и другие. Не случайно H.C. Таганцев в своих лекциях по уголовному праву

Кудрявцев В.Н.Социальные отклонения. - М., 1989. C. 244.

2 Ольков С. Г. Уголовно-процессуальные правонарушения. Тюмень, 1996. - С. 20, 21. 
на сей счет пишет, что с непокорством Зиждителю мира, с вредоносным посягательством на интересы ближних встречаемся мы на первых страницах священных преданий веры, и о тех же проявлениях зла и порока говорит нам ежедневная хроника текущей жизни ${ }^{3}$. Что касается преступлений, - пишет А.И. Долгова, - то история их столь же продолжительна, сколь же продолжительна история рода человеческого на Земле 4 .

B.Н. Кудрявцев и В.Е. Эминов отмечают, что раздумья о том, что за феномен, кто такие преступники, почему они совершают преступления, можно найти в трудах многих ученых с древнейших времен: философов, историков, правоведов, психологов, социологов и психиатров 5 .

«Преступность» - центральное понятие в криминологии. Но, как всегда бывает в науке, наименее ясное и определенное ${ }^{6}$. Не случайно И.И. Карпец в своей монографии «Преступность: иллюзии и реальность», пытаясь дать ее определение, в конце концов, заключил, что можно было бы найти еще немало определений преступности. Но достаточно. Западные ученые, как правило, не дают развернутых определений из убеждения в их ненужности или невозможности их дать. Разнобой же в определениях, проистекающий из разных методологических подходов к преступности, очевиден, и нередко определение становится своего рода визитной карточкой ученого, отражающей его основную специальность. Однако палитра определений (а значит, и подходов) впечатляет разносторонностью7.

Л.И. Спиридонов рассматривает преступность как «один из параметров общества, характеризующих состояние социального механизма, рассогласованность между его составными частями» ${ }^{8}$.

Д.А. Шестаков под этим явлением понимает «свойство классового общества порождать массо-

\footnotetext{
3 Таганцев Н.С. Русское уголовное право. Лекции. Часть общая: в 2 т.- М., 1994. - Т. 1. - С. 4.

4 Криминология: учебник для вузов / под общ. ред. А.И. Долговой. - М., 2005. - С. 6.

Криминология: учебник / под ред. В.Н. Кудрявцева и В.Е. Эминова. - М., 2002. - С. 3.

6 Гилинский Я.И. Девиантология: социология преступности, наркотизма, проституции, самоубийств и других «отклонений». - СПб., 2004. - С. 65.

7 Карпец И.И. Преступность: иллюзии и реальность. - М., 1992. - С. 15.

8 Спиридонов Л.И.Социология преступности. - М., 1978. C. $22,23$.
}

вое совершение опасных для него деяний» ${ }^{9}$. Однако в этих определениях по существу отсутствуют указания на признаки определяемого предмета, и речь идет не о преступности, а ее общих причинах.

Криминология изучает закономерности преступности, в том числе ее характеристики, процессы ее детерминации, причинности, реакцию преступности на разного рода воздействия на нее, разрабатывает пути борьбы с преступностью.

В течение последних столетий по различным проблемам, связанным с изучением преступности, было подготовлено огромное количество научных статей и монографий, в том числе носящих фундаментальный характер ${ }^{10}$.

Итак, в итоге огромной интеллектуальной работы многих поколений криминологов, ученых в области уголовного права и процесса у криминалистов постепенно сформировались современные представления о преступности и ее различных структурных составляющих, которые находят свое отражение в действующем уголовном, уголовно-процессуальном, уголовно-исполнительном законодательстве и соответствующей практической деятельности.

С середины 70-х голов XX столетия в советской криминологии возникли отрасли, освещающие взаимосвязь преступности с отдельными функциональными общественными системами. Семейная криминология (криминофамилистика), возникшая в 70-х годах в Санкт-Петербурге, исследует взаимосвязь института семьи и преступности. Она изыскивает возможности сдерживания преступности посредством воздействия на семью. Также, помимо общетеоретических работ появились достаточно глубокие, в том числе диссертационные исследования о влиянии семьи на различные виды преступной активности, в частности, на корыстное преступное поведение (Ф.Н. Аббасов). Вместе с тем остается недостаточно изученной имеющая пер-

\footnotetext{
9 Шестаков Д.А. На криминологическом семинаре / Правоведение. - 1981. — № 2. - С. 105, 106.

10 См.: об этом подробнее: Ч. Беккариа (1738-1794) «О преступлениях и наказаниях», И. Бентам (1748-1832) «Введение в основания нравственности и законодательства», «Рассуждения о гражданском и уголовном законоположении»; А. Кетле (1796-1874) «Социальная система и законы, ею управляющие»; Ч. Ломброзо (1835-1909) «Преступление», «Новейшие успехи науки о преступнике»; Э. Феррии (1856-1929) «Уголовная социология»; Тард (1843-1904) «Философия наказания»; П.А. Сорокин (1889-1968) «Преступление и кара, подвиг и награда»; Р. Мертон (1910) «Социальная структура и аномия»; Э. Сатерленд (1882-1950) «Принципы криминологии»; Г.С. Беккера (1930) «Преступление и наказание: экономический подход».
} 
спективу разработки актуальная проблема взаимосвязи семьи и рецидива преступлений.

Говоря о преступности, как о сложнейшем социальном явлении, хотелось бы особо отметить, что такая разновидность преступности, как преступность среди несовершеннолетних, всегда вызывает у ученых повышенное внимание ${ }^{11}$. И это вполне обоснованно, поскольку молодое поколение является естественным резервом социального развития, а нарушения уголовного закона лицами юного возраста, их распространенность не только свидетельствуют о существующих недостатках воспитания, условий для включения молодежи в жизнедеятельность общества, но и в значительной мере выступают в качестве прогностической характеристики преступности в целом.

По мнению А.И. Долговой, выделение преступности несовершеннолетних позволяет более глубоко изучать ее особенности, специфику детерминации, причинности, а также разрабатывать дифференцированные меры специального ее предупреждения. Не учитывать криминологически значимых особенностей преступности несовершеннолетних - значит не обеспечивать целенаправленный и дифференцированный подход к борьбе с ней ${ }^{12}$. Мы разделяем данную точку зрения и полагаем, что преступность несовершеннолетних обладает рядом специфичных, присущих только ей характеристик. Их выделение, детальное рассмотрение и изучение предоставит возможность выработки более эффективных мер предупреждения исследуемого вида преступности.

Вместе с тем при рассмотрении преступности несовершеннолетних следует иметь в виду ее целостность как сложного, системно-структурного социального явления, а также диалектическую взаимосвязь и взаимодействие разных ее подвидов (подростков 14-15 лет, 16-17 лет, гендерного различия $)^{13}$.

Преступность несовершеннолетних имеет ряд отличительных особенностей, которые проявляются в первую очередь в причинном комплексе и мотивации формирования преступного поведения и, как следствие, в ее уровне и тенденциях развития.

\footnotetext{
11 См.: Криминология / под ред. В.Н. Бурлакова. - СПб, 1998.

12 Криминология / Под общ. ред. А.И. Долговой. - 4-е изд., перераб. и доп. - М., 2010. - С. 889.

13 Там же.
}

В России исследованию рассматриваемой нами проблемы посвящены труды ряда авторов ${ }^{14}$.

Резкое социально-экономическое расслоение общества особенно болезненно воспринимается детьми и подростками. Увеличивающийся разрыв между реальными доходами и привлекательными жизненными стандартами, невозможность достижения последних правомерными способами обусловили интенсивное вовлечение несовершеннолетних даже из относительно благополучных в социальном смысле семей в криминальную деятельность или вызвали высокую степень психологической готовности к этой деятельности ${ }^{15}$. Возникают конфликты на почве социально-экономических контрастов, разрешаемые, к сожалению, зачастую криминальным путем.

Итак, кто же такие несовершеннолетние, совершающие преступные деяния?

Несовершеннолетние преступники - это лица, совершающие противоправные действия в раннем возрасте, позже, как правило, значительно труднее поддаются исправлению и в итоге составляют основной резерв для взрослой и рецидивной преступности.

По мнению ряда авторов, а именно Ю.Ф. Кваши, А.С. Зайналабидова, А.П. Зрелова, Д.Ю. Тамбовцева, Н.А. Свистуновой, М.В. Краснова, преступность несовершеннолетних объясняется: избранием несовершеннолетними антисоциального образа поведения в связи с неадекватной оценкой обстоятельств и отсутствием жизненного опыта в целях

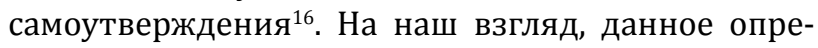
деление преступности несовершеннолетних недостаточно полно. Полагаем, что оно не содержит ряд признаков, которые присущи данному социальному явлению.

В узком понимании под преступностью несовершеннолетних можно рассматривать преступления, совершаемые лицами в возрасте от 14 до 18 лет. Однако в силу разных причин такое ограничение возраста весьма узко.

\footnotetext{
14 См.: Об этом подробнее: А.С. Автономов, 3.А. Астемиров, Н.Е. Борисова, В.Н. Бурлаков, С. Е. Вицин, В.Ф. Волохова, А.В. Воробьев, А.И. Долгова, В.П. Емельянов, В.Д. Ермаков, С. М. Иншаков, В.П. Кашепов, В.А. Кирнос, В.А. Колесников, Н.И. Крюкова, Н.Ф. Кузнецова, С. П. Минина, Г.М. Миньковский, Д.А. Шестаков, А.С. Шляпочников. 15 Криминология / под общ. ред. А.И. Долговой. - М., 2002. - C. 771.

16 См.: Криминология / под общ. ред. Ю.Ф. Кваши. Ростов-на-Дону, 2002.
} 
Обращаясь к проблеме преступности несовершеннолетних, следует исходить из того, что она представляет собой часть преступности в обществе, которая развивается под воздействием тех же факторов, что и преступность в целом. В силу этого при изучении преступности лиц в возрасте от 14 до 18 лет используются общекриминологические характеристики, показатели, а также иные категории. В то же время анализ должен быть направлен на выявление факторов и обстоятельств, значимых именно для преступности несовершеннолетних, позволяющих установить ее специфику и необходимые меры воздействия.

В научной литературе, и в частности, по мнению Президента Российской криминологической ассоциации А.И. Долговой, преступность несовершеннолетних представляет собой особый объект криминологического исследования, который рассматривается в следующих позициях:

1) общеправовых, как предусмотренность специальных глав в Уголовном, Уголовно-процессуальном, Уголовно-исполнительном кодексах, содержащих особенности привлечения к уголовной ответственности несовершеннолетних, расследования данной категории дел, а также назначения и его исполнения;

2) криминологические, как специфика:

a) преступлений несовершеннолетних (виды, формы, мотивы);

б) личности несовершеннолетнего (т.е. незначительный возраст и период ее формирования, ограниченная дееспособность, динамика содержания социально-ролевых и социальнопсихологических функций);

в) комплекса причин и условий преступности;

г) результативности мер специального профилактического воздействия ${ }^{17}$.

Несмотря на пристальное внимание к рассматриваемым проблемам ученых и практиков интерес к ним не снижается.

Преступность несовершеннолетних как социальная проблема продолжает оставаться в центре внимания учёных, государственных и общественных институтов. Это объясняется особенностями подростковой преступности, постоянным изменением социальных условий и законодательства, а также гуманными соображениями, необходимостью оградить подрастающее

17 Криминология: учебник для вузов / под общ. ред. А.И. Долговой. - М., 2010. - С. 890. поколение от вовлечения в противоправную деятельность ${ }^{18}$.

Негативные процессы, сопровождающие социально-экономические, политические и другие изменения в России, вызвали небывалое обострение криминальной ситуации. Под воздействием микро- и макросреды происходят заметные количественные и качественные изменения преступности несовершеннолетних - основы для воспроизводства общей преступности ${ }^{19}$.

Анализ преступности несовершеннолетних, с одной стороны, инструмент выявления криминогенных факторов в социуме, а с другой - база для прогноза преступности в целом.

Криминализация детей и подростков - это криминализация будущего нашей страны. По процессам, происходящим в детской и молодежной среде, мы можем с большой долей вероятности судить о том, каким будет наше общество в перспективе, в том числе какой будет преступность.

Помимо исследовательских и прогностических аспектов изучения преступности несовершеннолетних есть еще один - гуманитарный. Дети относятся к числу наименее защищенных социальных групп населения. Такое направление воздействия, как профилактика преступности в смысле защиты от нее, защиты от поражения социальных групп «криминальным вирусом», имеет наибольшее значение именно применительно к несовершеннолетним: детям и молодежи ${ }^{20}$. К сожалению, уровень криминальной пораженности данной части населения в современный период достаточно высокий.

Следует отметить, что специфика преступности несовершеннолетних может быть рассмотрена как обусловленная комплексом взаимосвязанных факторов, относящихся к возрастным, социальным, психологическим особенностям несовершеннолетних, специфике социального статуса ${ }^{21}$.

18 Кошелева Е.В. Криминологическое изучение влияния социально-негативных свойств семьи на преступность несовершеннолетних: дис. ... канд. психолог. наук. - Москва, 2005. - C. 3

19 Там же.

20 См.: Сморгунова Н.Ф. Предупреждение беспризорности среди детей и подростков в России (20-90-е гг. XX в.): автореферат ... канд. пед. наук. - Владимир, 1998.

21 См.: Алексеев А.И. Криминология. - М., 1998; Карпец И.И., Эминова В.Е. Криминология. - М., 1992; Лунеев В.В. Преступность ХХ века. - М., 1997. 
Установление таких специфических черт, обусловливающих правонарушающее поведение несовершеннолетних, особенности их качественных и количественных параметров, их анализ являются основой для разработки мер предупреждения, ориентированных на применение в отношении данной возрастной группы.

От того, какие перспективы развития в настоящее время будет иметь исследуемая нами проблема, во многом зависят состояние и тенденции преступности в будущем, и даже более широко нравственный климат в обществе ${ }^{22}$.
Итак, под преступностью несовершеннолетних следует понимать социально-правовое, негативное, общественно опасное, исторически обусловленное, устойчивое явление, представляющее собой систему преступлений совершенных лицами, не достигших совершеннолетия (восемнадцати лет), на определенной территории, а также за определенный период времени. Данное явление обладает повышенной общественной опасностью, так как именно несовершеннолетние лица являются основным резервом пополнения рядов взрослой, а также рецидивной преступности.

\section{Библиография:}

1. Гилинский Я.И. Девиантология: социология преступности, наркотизма, проституции, самоубийств и других «отклонений». - СПб., 2004.

2. Кудрявцев В.Н. Социальные отклонения. - М., 1989.

3. Карпец И.И. Преступность: иллюзии и реальность. - М., 1992.

4. Шестаков Д.А. На криминологическом семинаре / Правоведение. - 1981. — № 2.

5. Ольков С. Г. Уголовно-процессуальные правонарушения. - Тюмень, 1996.

6. Прялухина А.В. Социально-психологические детерминанты и особенности подростковой безнадзорности: автореф. дис. ... канд. психол. наук. - М., 2005.

7. Спиридонов Л.И. Социология преступности. - М., 1978.

8. Таганцев Н.С. Русское уголовное право. Лекции. Часть общая: в 2 т. - М., 1994. - Т. 1.

9. Новикова Ю.В. Методологические начала криминологической характеристики преступности (преступлений) // Актуальные проблемы российского права. - 2013. - 11. - C. 1488-1492. DOI: 10.7256/1994-1471.2013.11.8097.

10. Слюсарева Н.Д. Роль прокуратуры в предупреждении преступлений против семьи // Актуальные проблемы российского права. - 2012. - 3. - С. 266-274.

11. А. Э. Жалинский Обновление криминологии // Право и политика. $-2012 .-5 .-$ С. 828-835.

12. Бережнова Н.Д. Оперативное использование психологических факторов спецконтингента в предупредительной деятельности // Административное и муниципальное право. - 2013. - 2. - С. 113118. DOI: 10.7256/1999-2807.2013.02.3.

13. Астишина Т.В., Маркелова Е.В., Обгольц И.А. Предупреждение полицией преступлений несовершеннолетних // NB: Российское полицейское право. - 2013. - 1. - C. 45-64. DOI: 10.7256/23064218.2013.1.762. URL: http://www.e-notabene.ru/pm/article_762.html

14. Трегубова Е.В. Административные запреты в сфере осуществления полицейской деятельности // NB: Российское полицейское право. - 2013. - 1. - C. 25-44. DOI: 10.7256/2306-4218.2013.1.718. URL: http://www.e-notabene.ru/pm/article_718.html

15. О. Л. Дубовик Чувство безопасности граждан в Польше. Идентификация и противодействие современным угрозам // Национальная безопасность / nota bene. - 2011. - 5. - C. 188-193.

\section{References:}

1. Gilinskii Ya.I. Deviantologiya: sotsiologiya prestupnosti, narkotizma, prostitutsii, samoubiistv i drugikh «otklonenii». - SPb., 2004.

2. Kudryavtsev V.N.Sotsial'nye otkloneniya. - M., 1989.

22 См.: Прялухина А.В. Социально-психологические детерминанты и особенности подростковой безнадзорности: автореф. дис. ... канд. психол. наук. - М., 2005. 


\section{Административное и муниципальное право 5 (77) 2014}

3. Karpets I.I. Prestupnost': illyuzii i real'nost'. - M., 1992.

4. Shestakov D.A. Na kriminologicheskom seminare / Pravovedenie. — 1981. — № 2.

5. Ol'kov S.G. Ugolovno-protsessual'nye pravonarusheniya. - Tyumen', 1996.

6. Pryalukhina A.V. Sotsial'no-psikhologicheskie determinanty i osobennosti podrostkovoi beznadzornosti: avtoref. dis. ... kand. psikhol. nauk. - M., 2005.

7. Spiridonov L.I. Sotsiologiya prestupnosti. - M., 1978.

8. Tagantsev N.S. Russkoe ugolovnoe pravo. Lektsii. Chast' obshchaya: v 2 t. - M., 1994. - T. 1.

9. Novikova Yu.V. Metodologicheskie nachala kriminologicheskoi kharakteristiki prestupnosti (prestuplenii) // Aktual'nye problemy rossiiskogo prava. - 2013. - 11. - C. 1488-1492. DOI: 10.7256/19941471.2013.11.8097.

10. Slyusareva N.D. Rol' prokuratury v preduprezhdenii prestuplenii protiv sem'i // Aktual'nye problemy rossiiskogo prava. - 2012. - 3. - C. 266-274.

11. A. E. Zhalinskii Obnovlenie kriminologii // Pravo i politika. - 2012. - 5. - C. 828-835.

12. Berezhnova N.D. Operativnoe ispol'zovanie psikhologicheskikh faktorov spetskontingenta v predupreditel'noi deyatel'nosti // Administrativnoe i munitsipal'noe pravo. - 2013. - 2. - C. 113-118. DOI: 10.7256/19992807.2013.02.3.

13. Astishina T.V., Markelova E.V., Obgol'ts I.A. Preduprezhdenie politsiei prestuplenii nesovershennoletnikh // NB: Rossiiskoe politseiskoe pravo. - 2013. - 1. - C. 45-64. DOI: 10.7256/2306-4218.2013.1.762. URL: http://www.e-notabene.ru/pm/article_762.html

14. Tregubova E.V.Administrativnye zaprety v sfere osushchestvleniya politseiskoi deyatel'nosti // NB: Rossiiskoe politseiskoe pravo. - 2013. - 1. - C. 25-44. DOI: 10.7256/2306-4218.2013.1.718. URL: http://www.enotabene.ru/pm/article_718.html

15. O. L. Dubovik Chuvstvo bezopasnosti grazhdan v Pol'she. Identifikatsiya i protivodeistvie sovremennym ugrozam // Natsional'naya bezopasnost' / nota bene. - 2011. - 5. - C. 188-193. 